\title{
Large scale laboratory investigation in the improvement of subgrade characteristics of clay soil stabilized with construction demolition waste
}

\author{
Baki Bagriacik \\ Department of Civil Engineering, Faculty of Engineering, Cukurova University, Adana, 01330, Turkey \\ Corresponding Author: bakibagriacik@gmail.com
}

$\begin{array}{ll}\text { Submitted } & : 03 / 05 / 2020 \\ \text { Revised } & : 23 / 04 / 2021 \\ \text { Accepted } & : 04 / 05 / 2021\end{array}$

\begin{abstract}
Earthquakes are a serious problem for a country, where necessary measures should be taken. In this context, buildings that have completed their economic life have been demolished in recent years. A lot of construction demolition waste (CDW) occurred from the destroyed buildings. These wastes were collected in the storage facilities and took up a lot of space. So, it is vital to use these wastes both by emptying the storage facilities and reusing them without harming the nature. An alternative method for reutilizing these wastes is soil improvement. In this context, the usability of CDW in the improvement of a clay soil was investigated. The bearing capacity ratios (BCR) and stress distributions of the clay soil were examined for different CDW ratios, different improvement depths (H/D), and different curing times. As a result, it was suggested that the optimum CDW ratio should be $14 \%$, the improvement depth should be 1.5, and the optimum curing time should be 14 days in clay soil. The findings obtained from largescale experiments and microstructure analyses showed that CDW is a waste that can be used in soil improvement.
\end{abstract}

Keywords: Soil improvement; Construction demolition waste; Clay soil; Model test; Reinforcement.

\section{INTRODUCTION}

We are in a period where the need for housing is increasing rapidly due to the increasing population in the cities. The use of land in construction is increasing along with population growth and rapid urbanization. For this reason, there is a demand today for agricultural lands that do not meet the required criteria in terms of engineering features. In these lands, the properties of the soil generally need to be improved before construction. So, soil improvements have become increasingly important in recent years. One of the most important objectives expected in soil improvement is increasing bearing capacity and decreasing settlement of the soil. There are many methods for soil improvement. One of these methods is improving the soil by using additives. Nowadays, the reutilization and recycling of waste have become severely prominent due to aspects such as transportation and storage costs increments taking place in the burden of taxes as a result of an increase in environmental awareness and a limited amount of natural resources (Huang et al. 2002; Kartam et al. 2004). One of these wastes is CDW. In recent years, CDW came 
into existence as a result of demolition, modification, reparation, strengthening, maintenance, and improvement work for some structures that have completed their economic life such as buildings, schools, hospitals, and industrial facilities. So, there is a high proportion of CDW nowadays (Rao et al. 2007; Nunes et al. 2007; Mulder et al. 2007), and as these ratios vary according to countries and cities, this waste has a large place in solid waste (Huang et al. 2002; Kartam et al. 2004). So, CDW is of great importance in terms of environmental and economical perspectives. CDW can comprise of some materials such as concrete, sand, gravel, bricks, ceramic, natural rock material, rubble, asphalt, wood, various kinds of metal, glass, fluorescent lamps, plastic, pieces of carpets, and isolation (Vieira and Pereira 2015). Among the CDW, concrete waste has the highest percentage in terms of weight (Rao et al. 2007). Many researchers suggested that these wastes should be recycled as recycling materials and proposed some methods. Initial studies on the recycling of construction materials out of CDW have been launched in 1939 (Rao et al. 2007). In some studies, it has been suggested that CDW can be used directly as an erosion preventer (Fonteboa and Abella, 2007), filling material (Oikonomou 2005; Rakshvir and Barai 2006; Nunes et al. 2007; Mulder et al. 2007; Rao et al. 2007; Fonteboa and Abella 2007; Vieira and Pereira 2015), and natural aggregate in concrete production (Huang et al. 2002; Kartam et al. 2004; Oikonomou 2005; Rakshvir and Barai 2006; Rao et al. 2007; Nunes et al. 2007; Mulder et al. 2007; Fonteboa and Abella 2007; Vieira and Pereira 2015). Apart from what has been mentioned, there are studies showing that the recycled aggregate can also be used as sewerage fillings, coating work for roads and parking areas, recycled sand, recycled masonry, roadbed material, drainage material in water tunnels, asphalt aggregates, and filling material at concrete block production (Kartam et al. 2004; Demir 2009; Mulder et al. 2007; Corinaldesi et al. 2002). CBR tests were carried out by O' Mahony and Milligan (1991) in order to determine the usability of shattered concrete and demolition wastes in subbase embankments by means of recycling. It was specified that CBR results of this waste are in close agreement with those of natural limestone aggregates. A large-scale direct shear test was carried out by Sivakumar et al. (2004) in order to perform recycled crushed concrete and recycled crushed bricks. It was pointed out that recycled concrete and brick pieces have significant shear strength values, and they can be used in various geotechnical applications. Laboratory experiments were carried out by Poon et al. (2006) to analyze the convenience of utilizing recycled concrete aggregate and recycled brick instead of natural aggregate in subbase embankments of roads. As a result, CBR values of $100 \%$ recycled concrete aggregates were stated to be slightly lower than those of the natural material. In addition, it was expressed that CBR values have further reduced as the ratio of recycled bricks increased. Laboratory experiments were performed by Arulrajah et al. (2011) on recycled bricks, and they analyzed the usability of these materials in subbase embankments of roads. It was determined that the recycled brick has unacceptably low shear strength values at high water contents. For this reason, it was suggested to use recycled brick with natural aggregates at lowerwater content. Effects of composition and compaction degrees of CDW on the mechanical properties of materials were analyzed by Leite et al. (2011). It was stated that the CBR and elasticity modulus values of CDW are the same as the natural aggregate used on the roads. Therefore, it has been suggested that CDW can be used as a substitute for natural aggregate. In another study, the effects of CDW and cement on the stabilization of sandy soils were investigated by Bagriacik and Mahmutluoglu (2020). Parameters such as optimum ratios of $\mathrm{CDW}$ and cement, improvement depths, and time factor were determined. As a result, the optimum mixing ratio, optimum improvement depth, and optimum improvement time were recommended as $10 \%$ CDW-6\% cement, $0.75 \mathrm{D}$, and 28 days, respectively. It is clear that CDW is in a quality to be recycled from the previous studies. Succeeding in the reutilization of CDW enables a series of advantages such as decreasing the amount of waste produced, preventing the consumption of natural resources, and improving the economy. CDW, which undergoes recycling procedures, reaches an economical significance by means of being reused in the same sector or other sectors. There are some areas of study to eliminate this material when examined in the literature. As a new method, it was used in soil improvement in geotechnical engineering in recent years. Very limited studies were found regarding the use of this material from previous studies. In these studies, the investigated parameters were very shallow. Therefore, in the scope of the study, important parameters for the improvement of clay soils with CDW have been investigated with large scale experimental studies. 


\section{MATERIAL AND METHOD}

\section{Material}

The clay soil (CS) samples used in the experiments were obtained from Adana, Turkey. CDW has been collected from the ruins of structure that has been demolished within the scope of an urban renewal work in Adana Province. The coordinates of the CS and CDW used in the experiments were shown in Table 1. A series of tests were performed in the laboratory in order to specify index properties of the CS and CDW. Liquid limit, plastic limit, and plasticity index of the soil have been obtained to be approximately 42\%, 24\%, and 18\% (ASTM D4318), respectively. The activity value and specific gravity of the CS were found as 0.83 and $27 \mathrm{kN} / \mathrm{m}^{3}$ (ASTM D854), respectively. Optimum water content and maximum dry weight of the CS via compaction tests were found to be $18.10 \%$ and $17.40 \mathrm{kN} / \mathrm{m}^{3}$ (ASTM D698), respectively. CS was determined as clay with low plasticity (CL) in accordance with the standard ASTM D2487. The soil was found not to be dispersive according to the results of the conducted dispersion test, which was based on observation. Calcite, quartz, and clay group minerals such as smectite, kaolinite, and vermiculite were detected in consequence of a detailed analysis of the clay. The CDW was pulverized into a granulated dust state by means of using special equipment. The pulverized samples were sieved from a $2 \mathrm{~mm}$ diameter sieve, and the amount of CDW passed under the sieve was prepared for the experiments. The specific gravity of the CDW was found as $27.3 \mathrm{kN} / \mathrm{m}^{3}$ (ASTM D854). Sieve analysis tests (ASTM D6913-04) were conducted on both samples, and the results are presented as gradation curves in Figure 1. XRF (Minipal 4) analyses were carried out to determine the chemical compositions of both samples of which the results can be seen in Table 2 .

Table 1. Coordinate of the place where samples are provided.

\begin{tabular}{|c|c|c|}
\hline Material & Latitude & Longitude \\
\hline CDW & 37.0489 & 35.3015 \\
\hline CS & 36.7383 & 35.5835 \\
\hline
\end{tabular}

Table 2. Chemical compositions of CS and CDW.

\begin{tabular}{|c|c|c|c|c|c|c|c|c|c|c|c|c|c|}
\hline Component & $\mathrm{CaO}$ & $\mathrm{SiO}_{2}$ & $\mathrm{Al}_{2} \mathrm{O}_{3}$ & $\mathrm{Fe}_{2} \mathrm{O}_{3}$ & $\mathrm{MgO}$ & $\mathrm{Na}_{2} \mathrm{O}$ & $\mathrm{SO}_{3}$ & $\mathrm{~K}_{2} \mathrm{O}$ & $\mathrm{Ti}_{2} \mathrm{O}_{2}$ & $\mathrm{TiO}_{2}$ & $\mathrm{P}_{2} \mathrm{O}_{5}$ & $\mathrm{MnO}$ & $\mathrm{LL}$ \\
\hline $\mathbf{C S}$ & 3.2 & 50.6 & 18.4 & 8.7 & 6.1 & 2.5 & - & 3.1 & - & 1.65 & 0.65 & 3.1 & 3.15 \\
\hline $\mathbf{C D W}$ & 58.4 & 19.2 & 8.7 & 5.6 & 4.3 & 1.2 & 1.1 & 0.8 & 0.4 & - & 0.3 & - & - \\
\hline
\end{tabular}

The necessary values of optimum water content to be utilized in the experiments for each mixture ratio were determined with proctor compaction tests (ASTM D698). The maximum dry unit weights (MDD) and the optimum water content (OWC) can be seen in Figure 2.

It was observed that the amount of water required for compression increased with the increase of the CDW ratio in the mixture. The necessary values of optimum water content to be utilized in the experiments for each mixture ratio were determined with proctor compaction tests (ASTM D698). The maximum dry unit weights (MDD) and the optimum water content (OWC) can be seen in Figure 2. It was observed that the amount of water required for compression increased with the increase of the CDW ratio in the mixture. It has been suggested that the reason for the increase in the amount of water required for the increased mixing ratio may be due to the high water absorption capacity of CDW. In addition, it was determined that the highest MDD value occurred at 14-percent mixing ratio. 


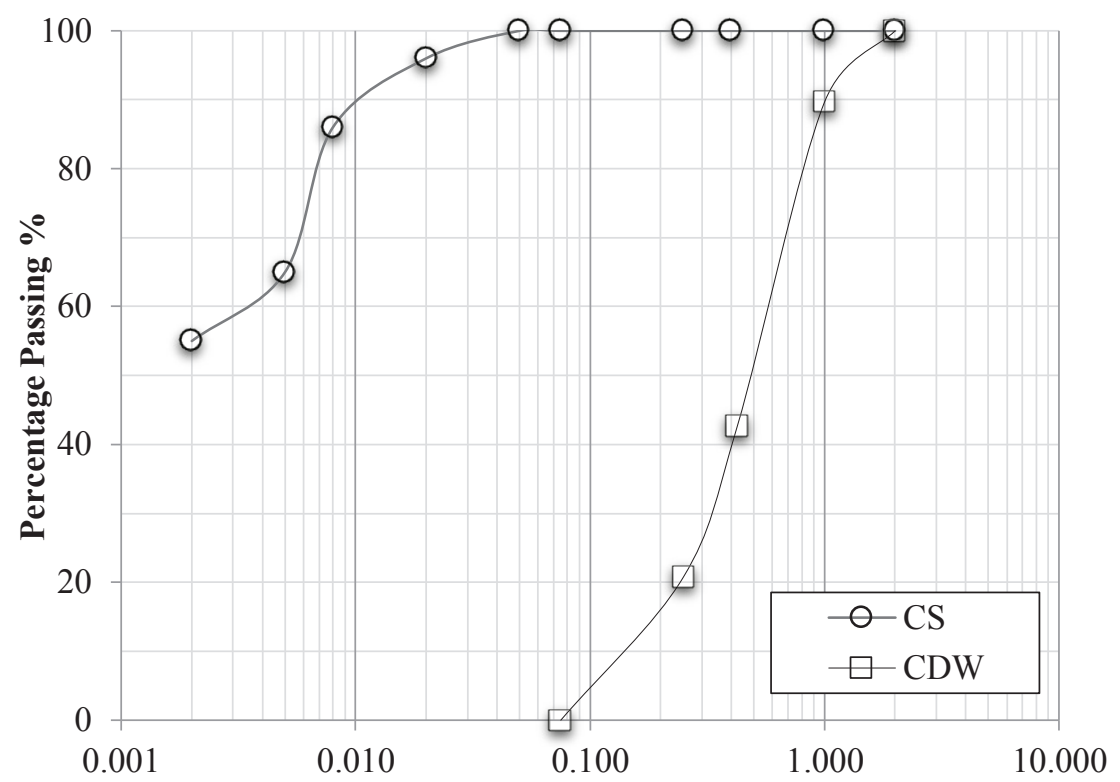

Particle Size (mm)

Figure 1. Gradation curves for CS and GMW.

๑Optimum Water Content (OWC)

口Maximum Dry Density (MDD)

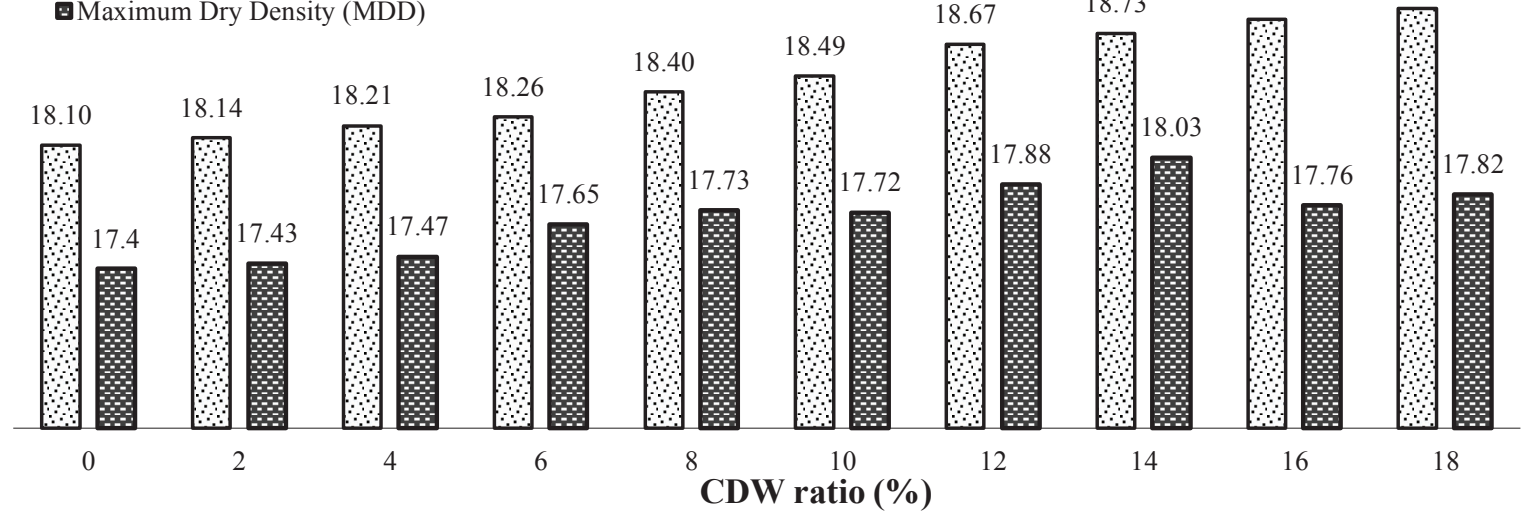

Figure 2. The optimum values of OWC and MDD for CDW ratios (OWC:\%, MDD: $\left.\mathrm{kN} / \mathrm{m}^{3}\right)$.

\section{METHOD}

CS and CDW obtained from the coordinates indicated in Table 2 were separated into smaller pieces. The CS and CDW were dried in an oven for a 24 -hour period at a temperature of $105 \pm 5^{\circ} \mathrm{C}$ and were granulated by a grinding machine. The optimum water content for different CDW ratios was found by compaction test. CS and CDW were 
prepared at optimum water content. The samples were kneaded until a homogenous water distribution was formed and were kept in the curing room for 24 hours to prevent moisture loss. At this stage, samples were prepared for large-scale experiments. A circular test box and model footing with internal dimensions of $600 \mathrm{~mm} \times 600 \mathrm{~mm}$ and $100 \mathrm{~mm} \times 10 \mathrm{~mm}$ (diameter $\mathrm{x}$ height) were used in the experiments (Figures 3-4). The test box is made of $10 \mathrm{~mm}$ thick steel profiles, and vertical steel profiles are mounted in the middle of the test box in order to increase the rigidity. The strain gauges were placed into the model test box's edges in order to control the occurrence of the boundary effect. During the loading of the foundation, it was observed that the values on the strain gauges were equal to zero. The soil was poured into the test box, and it was compressed with a specially prepared rammer under a constant standard energy (Dash et al. 2003). The weight of the rammer is $2 \mathrm{~kg}$. The fall height was kept at $20 \mathrm{~cm}$. Compaction was dropped approximately 80 times from a height of $20 \mathrm{~cm}$ for a fixed thickness layer. The fillings were placed in 2.5 $\mathrm{cm}$ layers in order to control the test conditions, and the required controls were made in each layer. A geogrid (square span geogrid with strengths of $22-48 \mathrm{kN} / \mathrm{m}$ for the $2-5 \%$ elongation and spans of $31 \mathrm{~mm}$ ) was placed at the interface of samples to enable separation. The measuring system was placed in the device after the soil sample is placed in the test box. The measuring system consists of two vertical displacement transducers, six strain gauges, and a load cell. The initial values of the measurement systems were reset. Finally, necessary controls were made to ensure the uniformity of the system and the load to be applied. The load was applied vertically and statically to the model footing center. The loading rate was kept constant during the experiment. Each experiment performed was waited until the bearing capacity was reached. During the experiments, the displacement, strain gauges, and load values were transferred to the data logger. The obtained displacement, strain gauges, and load values were converted into numerical values by means of the DS7 program on the computer. At the end of each experiment, the load and settlement curves were drawn, and the bearing capacity was determined. In addition, vertical stresses in the soil were measured.

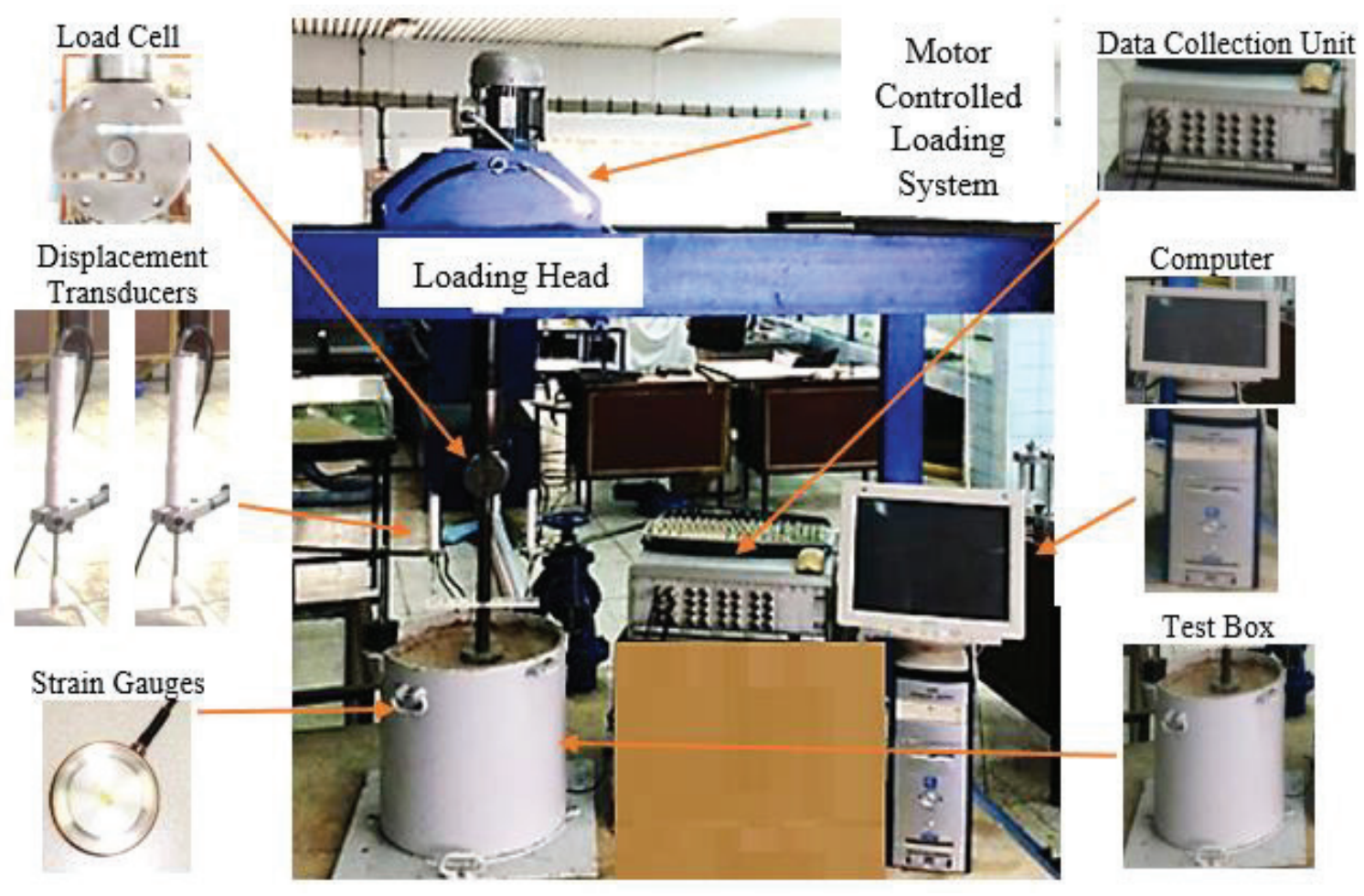

Figure 3. Experimental Setup. 

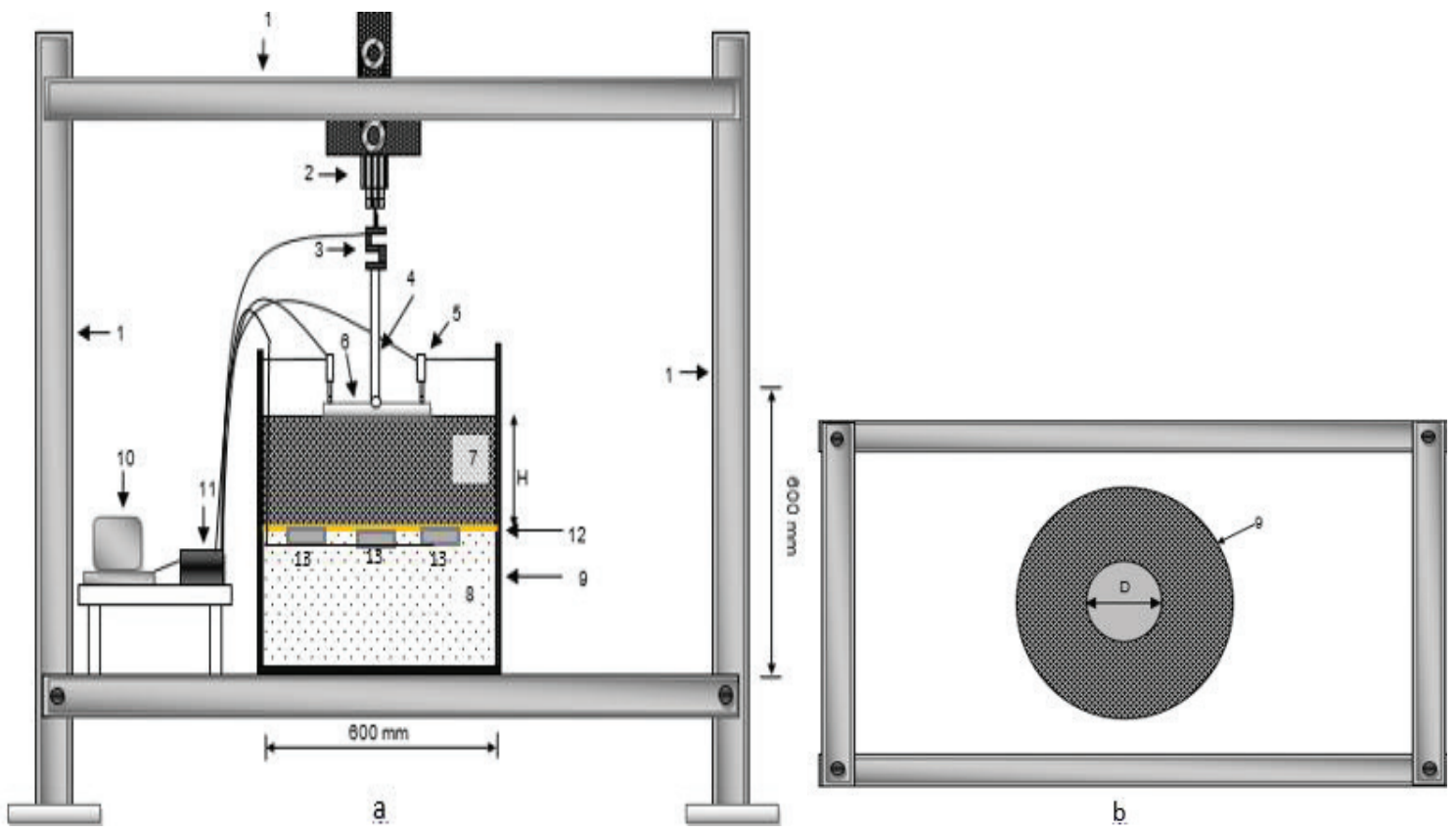

(1-Loading Frame, 2-Motor Controlled Loading System, 3- Load Cell, 4- Loading Head, 5-Displacement Transducers, 6- Model Footing, 7- Improved soil with CDW, 8- Clayey soil, 9-Test Box, 10-Computer, 11-Data Collection unit, 12- Geogrid, 13-Strain Gauges)

Figure 4. Experimental Setup (a: plan, b: section).

\section{RESULTS AND DISCUSSIONS}

For all experiments, the load capacity-settlement ratio graphs of the circular footing were obtained, and the failure loads were determined by using these graphs. Settlement ratio values (s/D) in the graphs were obtained by dividing the settlement of footing (s) by the diameter of footing (D) to a dimensionless value. The bearing capacity value is selected as the peak value of the load in the load-settlement curve. In order to express the increases in the bearing capacity of the system by the stabilized filling additive, the BCR value of the Bearing Capacity Ratio (Binquet et al. 1975) was calculated with the following formula. The findings obtained from the experimental study on the improvement of soils with construction demolishing waste are presented below.

BCR : $\mathrm{q}_{\mathrm{r}} / \mathrm{q}_{0}$ (BCR : bearing capacity ratio, $\mathrm{q}_{\mathrm{r}}$ : reinforced soil, $\mathrm{q}_{0}:$ unreinforced soil)

\section{Effect of Different Cdw Ratios on Bcr And Stress Distribution}

Large-scale laboratory experiments were carried out to determine the effect of CDW added to clay soil in different proportions on bearing capacity. CDW rate compatible with the literature was chosen as $2-18 \%$. Loaddisplacement values, BCR values, and stress variations at $2 \mathrm{D}$ depth due to the foundation for different $\mathrm{CDW}$ ratios were shown in Figures 5-6. From the results, it was observed that the BCR values increased in each CDW ratio up to a certain displacement, and then the BCR values remained constant due to the increasing displacement. The BCR values of the clay soil with the addition of CDW at different rates increased by 1.07, 1.29, 1.47, 1.84, 2.26, 2.31, 2.41, 
2.42, and 2.42, respectively. It was observed that the BCR value remained constant after $14 \% \mathrm{CDW}$. The ratio of $14 \% \mathrm{CDW}$ addition was decided to be satisfactory in such soil improvement work. In addition to not being able to provide any further improvement in soil at CDW ratios more than $14 \%$, the outcome that waste utilization is not carried out optimally would be taken into consideration. The vertical stress applied to the foundation decreased by $84 \%$ at the 2D depth of the clay soil. With the addition of CDW at different rates to the clay soil, this decrease is $90 \%, 91 \%, 92 \%, 92 \%, 93 \%, 95 \%, 98 \%, 98 \%$, and $99 \%$, respectively. The additional stresses decreased further with a horizontal distance from the center of the foundation at the same depth. Its effect was measured to disappear by $100 \%$ at the horizontal 3D distance from the foundation center. It has been observed that the CDW additive not only increases the bearing strength of the clay soil, but also reduces the additional stresses significantly. The addition of CDW prevented the vertical load due to the foundation from being transmitted to deeper depths by damping more than the clay soil. On the other hand, it was observed that this decrease remained constant after the $14 \% \mathrm{CDW}$ addition. Therefore, it is predicted that $14 \% \mathrm{CDW}$ addition is sufficient in terms of damping the stresses at depth.
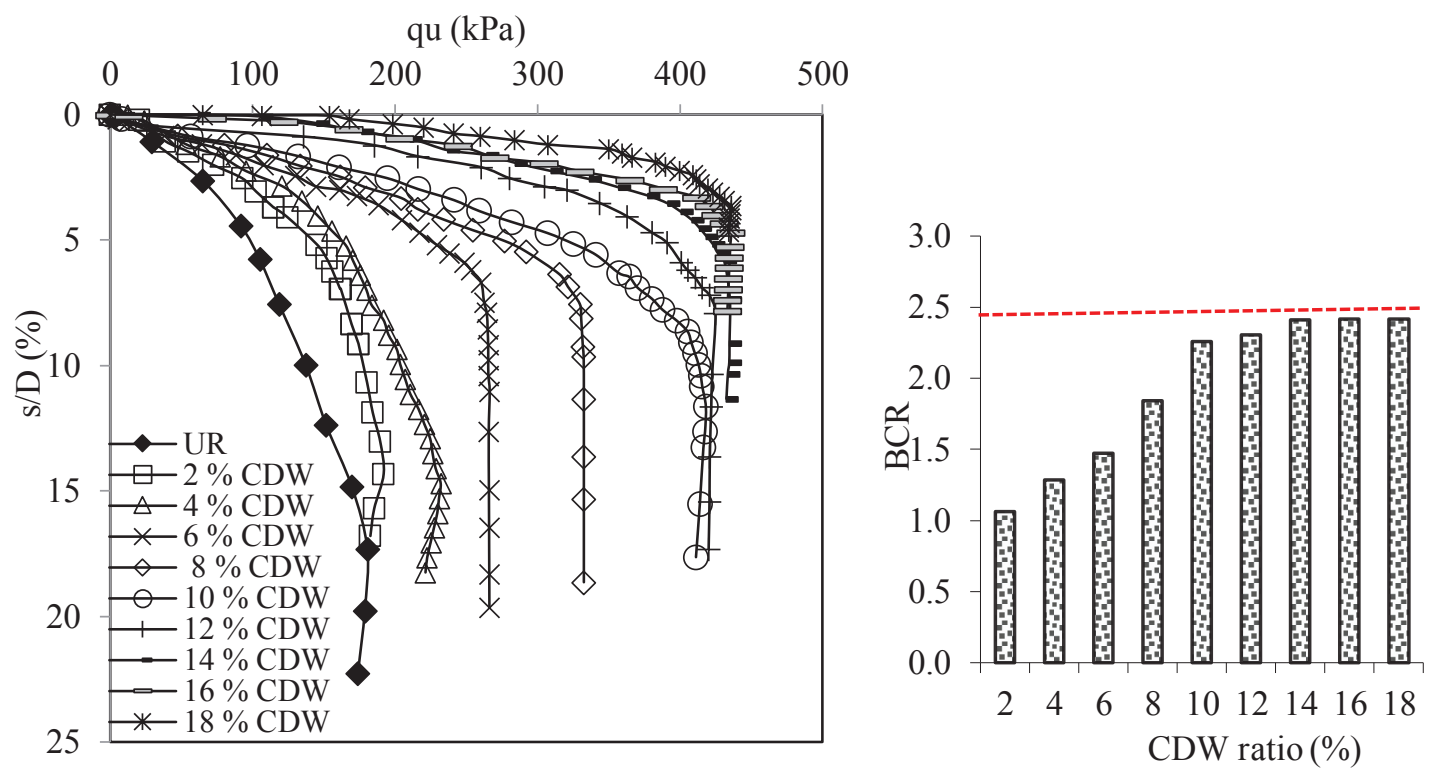

Figure 5. $\mathrm{q}_{\mathrm{u}}$ - s/D- BCR values for different CDW ratios (UR: Unreinforced Clay).

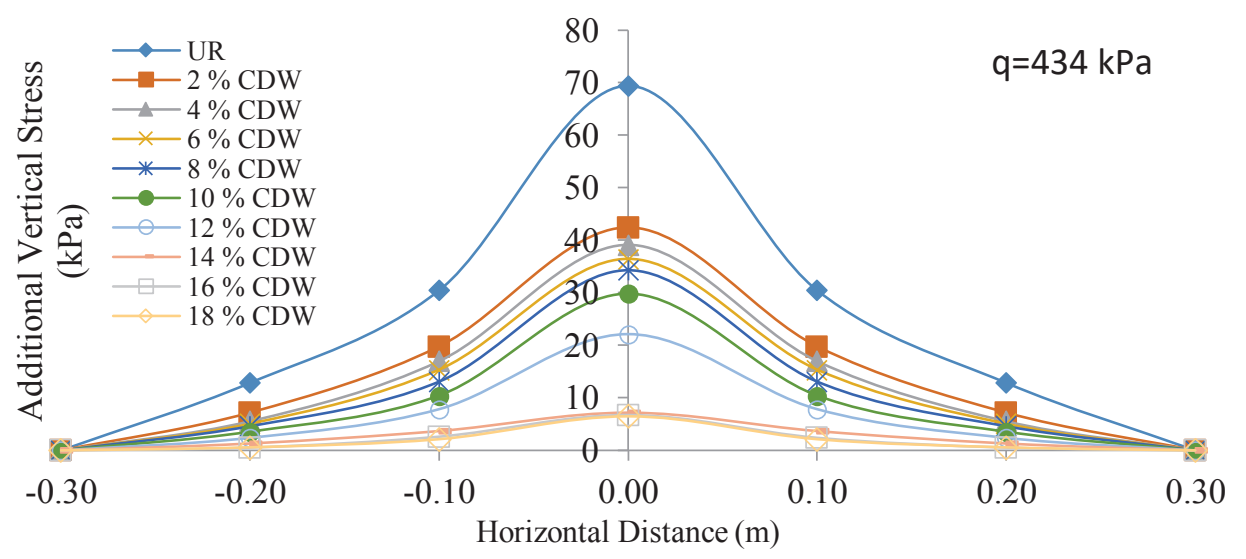

Figure 6. Stress Distribution for different CDW ratios (UR: Unreinforced Clay). 


\section{Effect of Improvement Depths on Ber and Stress Distribution}

Large scale experiments were implemented on the mixtures prepared at various CDW ratios of materials for different improvement depths with the objective to determine the effect of improvement depth. Load-displacement values, $B C R$ values, and stress variations at $2 \mathrm{D}$ depth due to the foundation for different improvement depth $(\mathrm{H} / \mathrm{D})$ were shown in Figures 7-8. It was determined that the lowest bearing capacity (qu $=180.53 \mathrm{kPa}$ ) (Bagriacik and Guner, 2020) was reached when the model test box was completely (UR) filled with clay soil. The highest bearing capacity $(\mathrm{qu}=435.00 \mathrm{kPa})$ was reached when the model test box was completely $(\mathrm{H} / \mathrm{D}=6.0)$ filled with clay soil prepared at the optimum CDW ratio. It was observed that as the improvement depth of the clay soil prepared in optimum CDW ratio increased, the bearing strength of the clay soil increased up to $434 \mathrm{kPa}$ values. BCRs increased by $1.12,1.29,1.74,2.02,2.28,2.40,2.40$, and 2.40 times for different improvement depths (H / D = 0.25-2.00). Significant improvements occurred up to a $\mathrm{H} / \mathrm{D}=1.5$, and it was seen that improvement remained constant after that depth. In relation to the obtained result, the optimum $\mathrm{H} / \mathrm{D}$ value was selected as 1.50 . According to the results obtained for different $H / D$, it was determined that it is sufficient to improve a certain depth $(H / D=1.5)$ instead of improving the entire soil in the field. It was observed that $84 \%$ of the applied vertical load was absorbed in 2D depth if the model test box was completely filled with clay soil. Depending on the increasing improvement depth, it was observed that the applied vertical load was absorbed in 2D depth by $91 \%, 92 \%, 93 \%, 95 \%, 96 \%, 98 \%, 98 \%$, and $99 \%$, respectively. It was determined that the highest damping occurred at $\mathrm{H} / \mathrm{D}=1.5$ and remained constant after this depth. Therefore, it is predicted that it would be appropriate to choose $\mathrm{H} / \mathrm{D}=1.5$ as the improvement depth. Similarly, it has been observed that there are similar rates of damping at 2D depth as you move away from the foundation center. It has also been determined that the stress value is completely damped from a 3D horizontal distance from the foundation center. It is thought that improving the soil at greater depths would be disadvantageous, as it would unnecessarily increase both cost and waste usage.
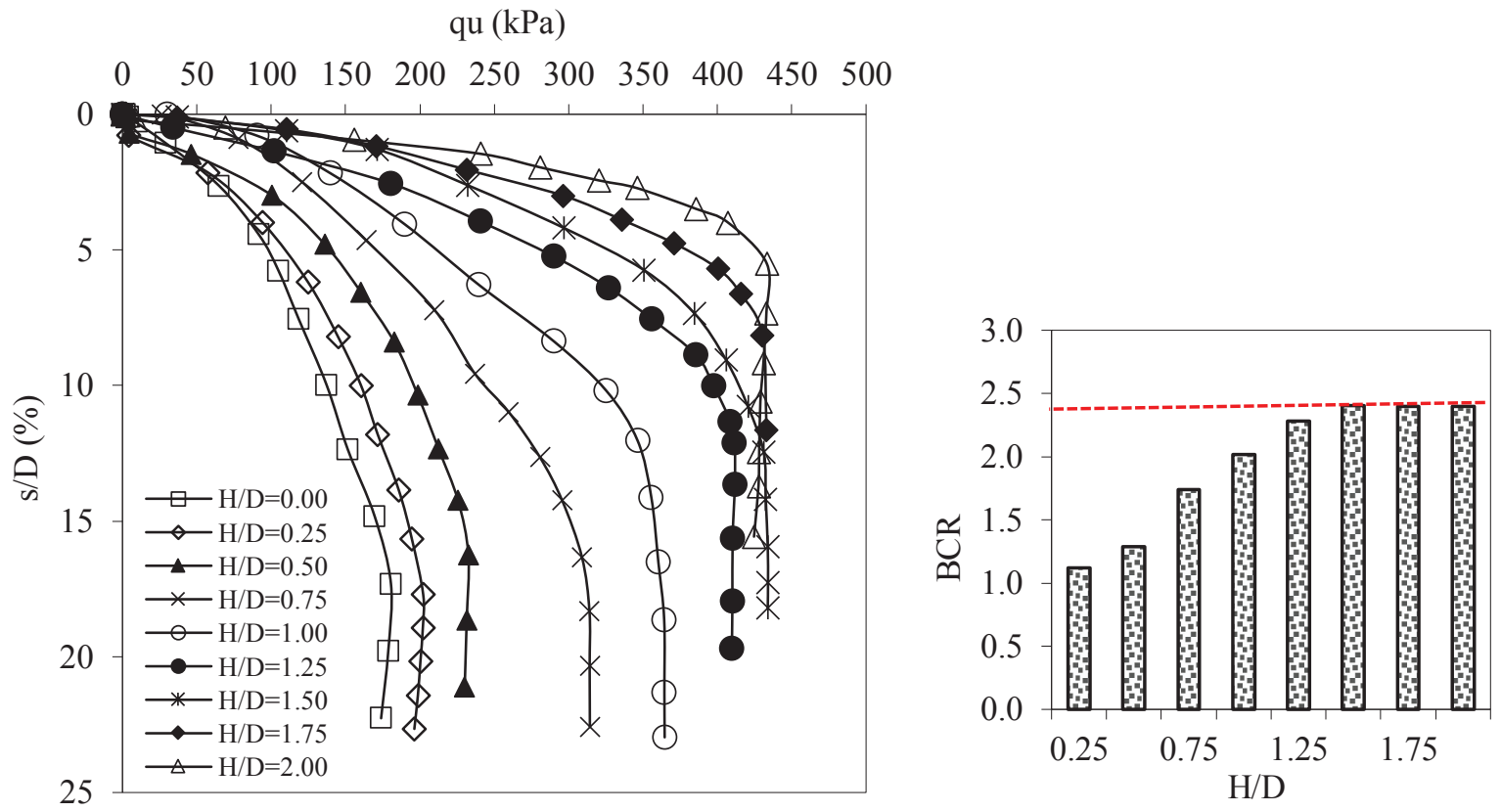

Figure 7. $\mathrm{q}_{\mathrm{u}}$ - s/D - BCR values for different Improvement Depth (H/D). 


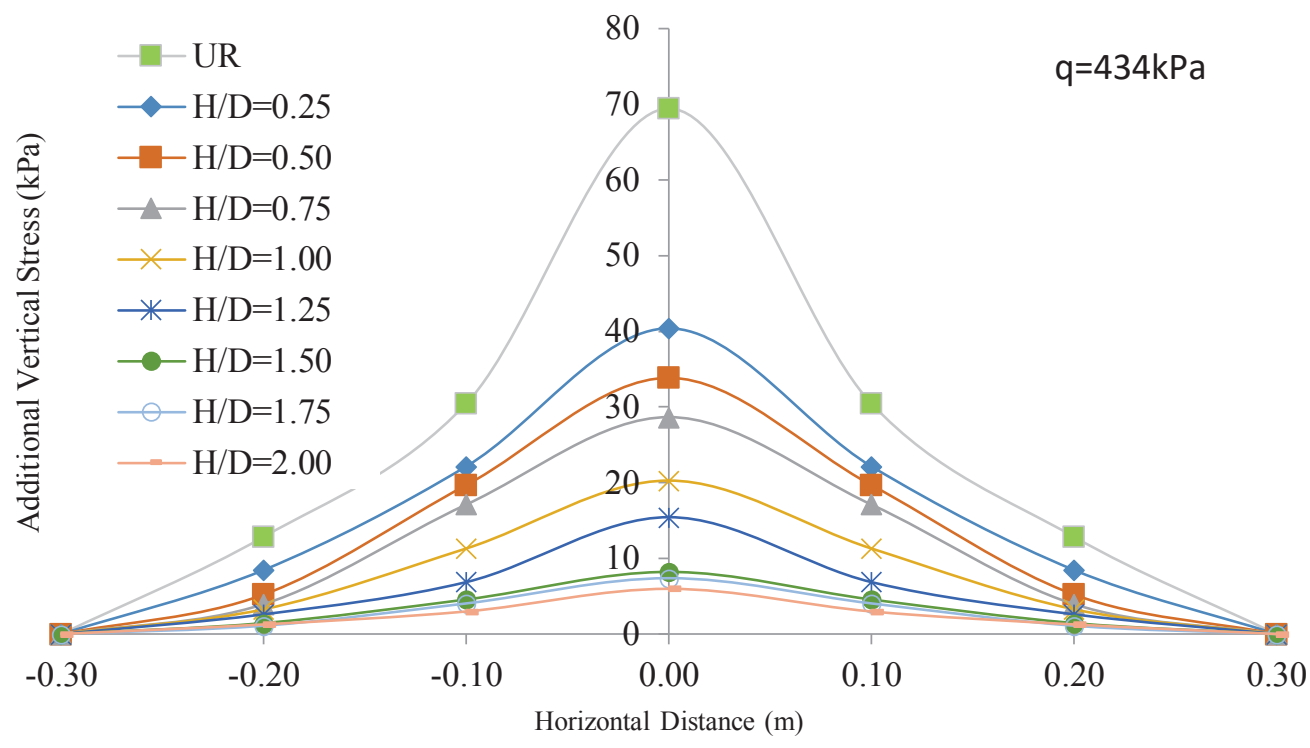

Figure 8. Stress Distribution for different Improvement Depth (H/D).

\section{Effect of Curing Time on Bcr and Stress Distribution}

In order to investigate the effect of curing time, a series of experiments were carried out on clay soil prepared from the optimum CDW ratio. In the experiments, the cure period was preferred for 1 day, 7 days, 14 days, and 28 days in accordance with the literature. Load-displacement values, BCR values, and stress variations at 2D depth due to the foundation for different curing time were shown in Figures 9-10. It was observed that as the curing time increases, the bearing power increases from $434 \mathrm{kPa}$ to $586 \mathrm{kPa}$ on the clay soil prepared with the optimum ratio of CDW. It was observed that the highest BCR value was reached after 14 days. After 14 days, the BCR value remained constant. When Calcium Oxide $(\mathrm{CaO})$, which has high ratio in the mixture, was mixed with optimum water, a chemical reaction occurred, and the bonding of the clay floor increased. The BCR of the clay soil increased with the increase in binding. After 14 days, the BCR reached its highest value. After 14 days, the BCR remained stable. The reason the BCR remained stable is because the hydration of Calcium Oxide ended in 14 days. For this reason, it is recommended to wait at least 14 days for superstructure works after the soil improvement works with CDW are completed. At the end of the 1st, 7th, 14th, and 28th days, the stresses in the 2D depth soil were damped at approximately $98 \%, 99 \%, 100 \%$, and $100 \%$, respectively. It was observed that the additional vertical stresses applied to the soil due to the foundation were completely absorbed after 14 days. It is understood from the stress values that at least 14 days is required for the completion of hydration in soil improvements with CDW. 

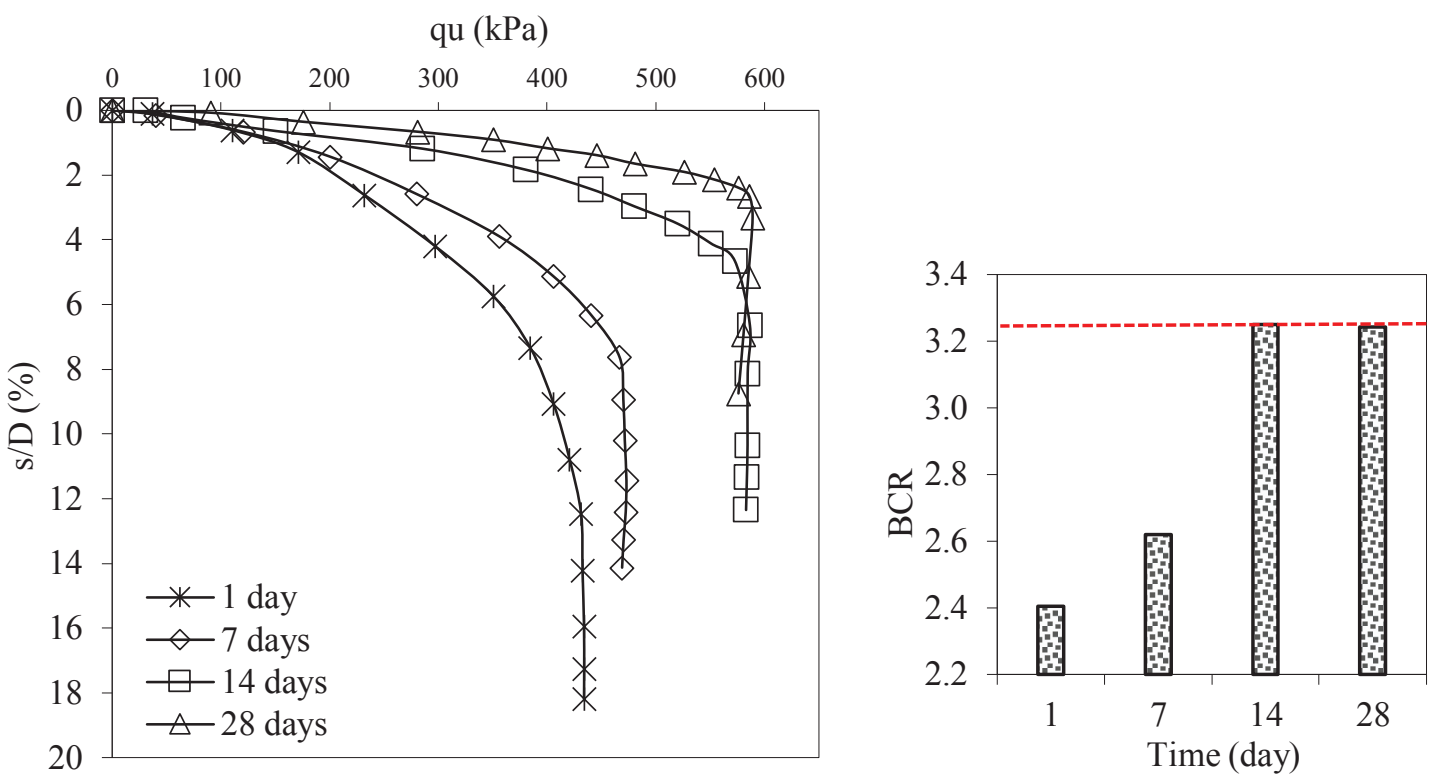

Figure 9. $q_{u}-s / D-B C R$ values for different Curing Time.

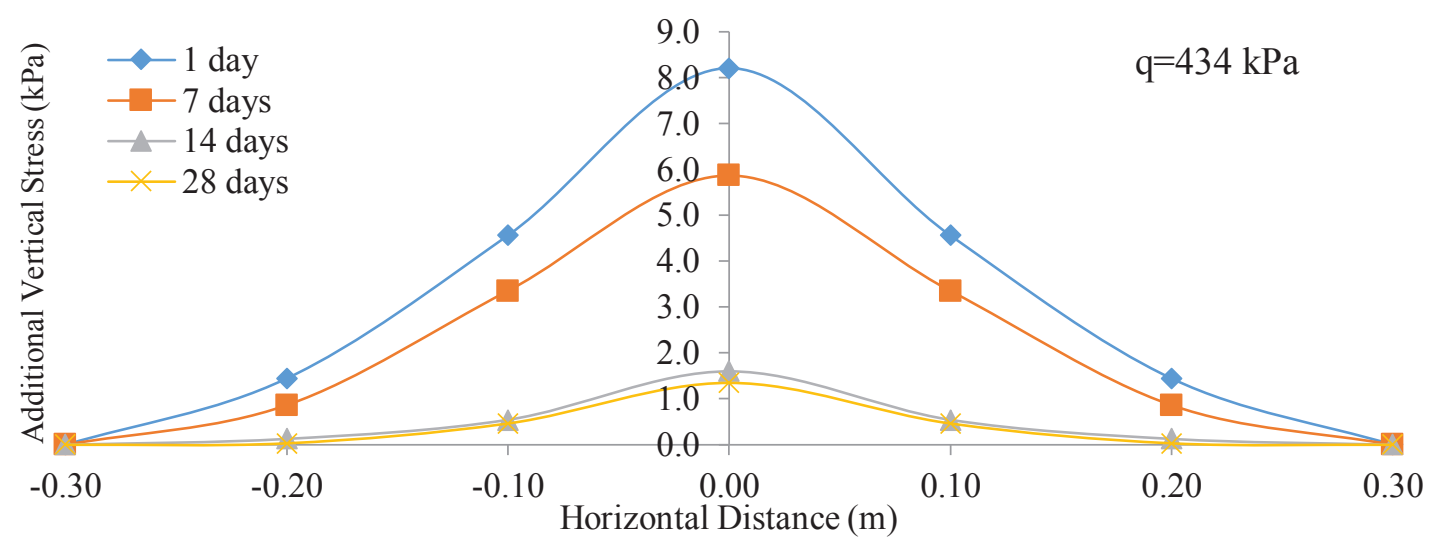

Figure 10. Stress Distribution for different Curing Time.

\section{EVALUATION OF MICROSTRUCTURE ANALYSIS}

The composition of the chemical element and the description of the micro structured surface of only clay, only CDW, and clay soil with stabilization of CDW were observed by using Scanning Electron Microscope (SEM). Furthermore, the microstructure surface image of the SEM test result is shown in Figure 11. The SEM/EDS test shows that the chemical content of clay was dominated by the elements of $50.60 \% \mathrm{SiO}_{2}, 18.40 \% \mathrm{Al} 2 \mathrm{O} 3,8.70 \%$ $\mathrm{Fe}_{2} \mathrm{O}$, and $3.20 \% \mathrm{CaO}$, the chemical content of CDW was dominated by the elements of $58.40 \% \mathrm{CaO}, 19.20 \% \mathrm{SiO}_{2}$, $8.70 \% \mathrm{Al}_{2} \mathrm{O}_{3}$ and $5.60 \% \mathrm{Fe}_{2} \mathrm{O}_{3}$ and the chemical content of Clay-CDW mixture was dominated by the elements of $39.90 \% \mathrm{SiO}_{2}, 34.00 \% \mathrm{CaO}, 10.30 \% \mathrm{Al}_{2} \mathrm{O}_{3}$ and $7.70 \% \mathrm{Fe}_{2}$. Moreover, it is seen that the microstructure of the soil 
becomes denser and more compact at Clay-CDW mixture. The $\mathrm{CaO}$ is also a component of the lime material, which improves the binder properties of the clay and shows time-dependent hardening. In addition, $\mathrm{SiO}_{2}$ is the main constituent element in the formation of pozzolanic cement that has the behavior of binding other minerals in clay, so that it becomes harder within a certain period of time. It was determined that the results of the strength tests of the Clay-CDW mixture were very good over time due to the good binding properties of the two components in the mixture. SEM displays an image by firing a high-energy electron beam of 1-20 keV. As can be seen from Figure 11, it is seen that it makes the mixture even more porous and rigid due to the $\mathrm{CaO}$ and $\mathrm{SiO}_{2}$ minerals present in the ClayCDW mixture made from SEM test.
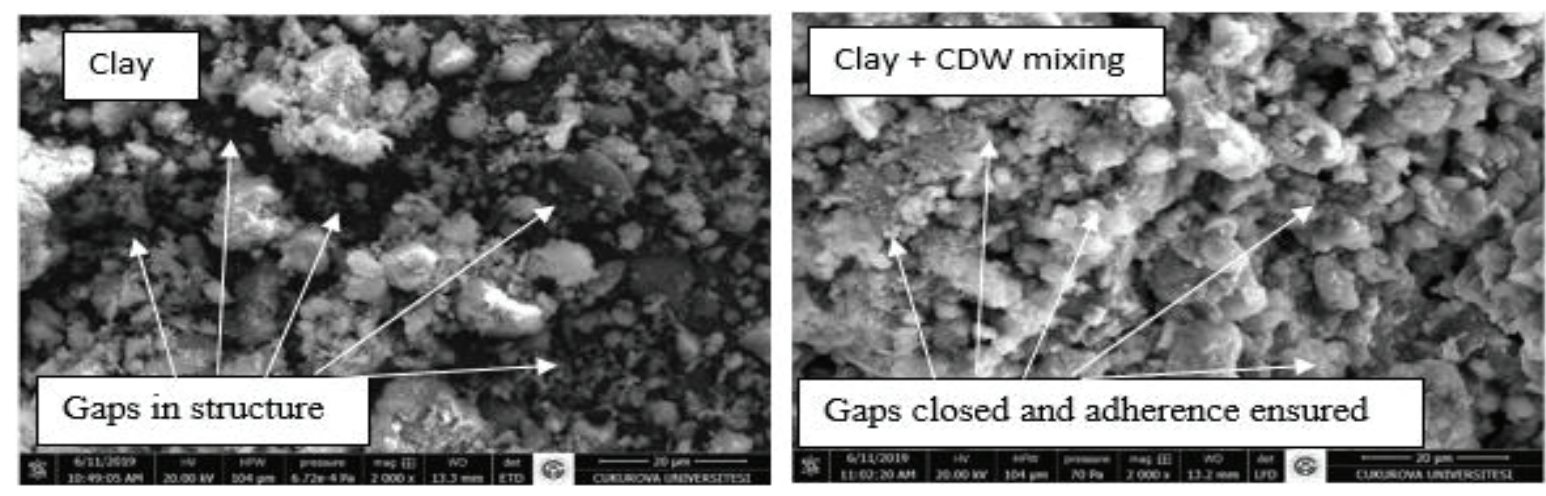

Figure 11. The scanning electron microscopy with energy dispersive spectroscopy.

\section{CONCLUSIONS}

Old buildings are demolished, and more robust buildings are built instead due to the increasing earthquakes in recent years. During the demolition of old buildings, large amounts of construction debris are generated. These wastes take up more space in the storage areas. Alternative methods are required for both the evacuation of landfills and the reuse of these wastes. In this study, the usability of CDW in soil improvement as an alternative method was investigated. The results obtained are listed below.

- After a series of large-scale laboratory experiments, it was determined that $14 \% \mathrm{CDW}$ addition was sufficient while improving clay soils. It was observed that when $14 \% \mathrm{CDW}$ was used in the improvement, the BCR increased approximately 2.41 times. In addition, the highest rate of absorption of the stresses in the soil along the vertical and horizontal plane occurred after the addition of $14 \% \mathrm{CDW}$. It is not recommended to add more CDW, because it has no extra effect on improving the soil, and the resources are not economically used. There are also studies on the use of different waste materials in the literature. For different wastes used (bottom ash; cement, rice hush ash, and calcium carbide; cement addition along with rubber fibers; alum sludge; sludge ash, drinking water treatment sludge, glass manufacturing waste, etc.), optimum amounts are specified. These amounts are, respectively, 30\% (Güllü 2014), 15\% (Liu et al. 2019), 7.5\% (Yadav 2019), 8\% (Shah et al. 2020), 7\% (Ayininuola and Ayodeji 2016), 10\% (Bagriacik and Guner, 2020), and 25\% (Mahmutluoglu and Bagriacik 2020).

- The highest BCR was measured at the improvement depth (H/D) 1.5. After this depth, the BCRs remained constant. Also, the highest stress damping of BCR in clay soil occurred at this depth (approximately 98\%). Therefore, considering the improvements in BCR and economy, it was suggested that the optimum value should be 1.5 within the improvement depths (H/D) investigated. Similarly, there are several studies in the literature to investigate the optimum improvement depth for different wastes. These wastes are drinking water treatment sludge and glass manufacturing waste. Improvement depths in these wastes were determined as 
2.25 (Bagriacik and Guner, 2020) and 1.75 (Mahmutluoglu and Bagriacik, 2020), respectively. CDW is thought to provide a more effective recovery on such clay soils than other wastes.

- After completing the ground improvement with CDW, it was suggested to start the superstructure construction at least 14 days later. In a similar study in the literature using glass manufacturing waste instead of CDW, at least 7 days were suggested as the optimum day. If there is a time limitation in the field application, using glass manufacturing waste instead of CDW was considered to be a more effective approach.

- From the SEM images, it was observed that there were free grains and voids on the clay floor. After mixing with $\mathrm{CDW}$, it was observed that these gaps were closed, and a more rigid structure was obtained. The formation of this rigid structure is thought to be due to the binding property of $\mathrm{CaO}$. The images obtained from SEM results support the results of large-scale experiments.

- There are many advantages of using CDW in ground improvement. One of them is that, instead of using traditional additives in improvement, an economical solution was produced by using CDW. Another is that the high percentage of CDW in landfills was destroyed without harming the environment. This study showed that CDW can be used effectively in soil improvement as an alternative method.

\section{REFERENCES}

Arulrajah, A., Piratheepan, J., Aatheesan, T. \& Bo, M.W. 2011. Geotechnical properties of recycled crushed brick in pavement applications. J Mater Civ Eng. 23(10): 1444-1452.

ASTM D4318 Standard Test methods for liquid limit, plastic limit, and plasticity index of soils.

ASTM D698 Standard test methods for laboratory compaction characteristics of soil using standard effort.

ASTM D854 Standard test methods for specific gravity of soil solids by water pycnometer.

ASTM D2487 Standard practice for classification of soils for engineering purposes.

ASTM-6913-04 AD Standard test methods for particle-size distribution (Gradation) of Soils

using sieve analysis.

Ayininuola, G. \& Ayodeji, I. 2016. Influence of sludge ash on soil shear strength. Journal of Civil Engineering Research. 6(3): 72-77.

Bagriacik, B. \& Mahmutluoglu, B.A. 2020. A new experimental approach to the improvement of sandy soils with construction demolition waste and cement. Arab J Geosci.; 13: 539.

Bagriacik, B. \& Guner, E.D. 2020. An Experimental investigation of reinforcement thickness of improved clay soil with drinking water treatment sludge as an additive. KSCE J Civ Eng. 24: 3619-3627.

Binquet, J. \& Lee, K.L. 1975. Bearing capacity tests on reinforced earth slabs ASCE. Journal of Geotechnical Engineering Division, 101(12): 1241-1255.

Corinaldesi, V., Giuggiolini, M. \& Moriconi, G. 2002. Use of rubble from building demolition in mortars. Waste Management. 22: 893-899.

Dash, S.K., Sireesh, S. \& Sitharam, T.G. 2003. Model studies on circular footing supported on geocell reinforced sand underlain by soft clay. Geotext. and Geomembranes. 21:197-219.

Fonteboa, B.G. \& Abella, F.M. 2007. Concretes with aggregates from demolition waste and silica fume materials and mechanical properties. Building and Environment. 43: 429-437.

Güllü, H. 2014. Factorial experimental approach for effective dosage rate of stabilizer: Application for finegrained soil treated with bottom ash. Soils and Foundations. 54(3): 462-477.

Huang, W.L., Lin, D.H., Chang, N.B. \& Lin, K.S. 2002. Recycling of construction and demolition waste via a mechanical sorting process. Res., Cons. and Recycling. 37: 23-37. 
Kartam, N., Al-Mutairi, N., Al-Ghusain, I. \& Al-Humoud, J. 2004. Environmental management of construction and demolition waste in kuwait. Waste Management. 24: 1049-1059.

Leite, F.C., Motta, R.S., Vasconcelos, K.L. \& Bernucci, L. 2011. Laboratory evaluation of recycled construction and demolition waste for pavements. Construction and Building

Materials. 25:2972-2979.

Liu, Y., Chang, C.W., Namdar, A., She, Y., Lin, C.H., Yuan, X. \& Yang, Q. 2019. Stabilization of expansive soil using cementing material from rice husk ash and calcium carbide residue. Construction and Building Materials. 221: 1-11.

Mahmutluoglu, B. \& Bagriacik, B. 2021. Sustainable implementation of glass manufacturing waste and geogrids in the improvement of fine-grained soils. KSCE J Civ Eng. 00(0) : 1-13.

Mulder, E., Jong, T.P.R. \& Feenstra, L. 2007. Closed cycle construction: An integrated process for the separation and reuse of C\&D waste. Waste Management. 27: 1408-1415.

Nunes, K.R.A., Mahler, C.F., Valle, R. \& Neves, C. 2007. Evaluation of investments in recycling centres for construction and demolition wastes in brazilian municipalities. Waste Management. 27: 1531-1540.

Poon, C.S. \& Chan, D. 2006. Feasible Use of Recycled Concrete aggregates and crushedclay brick as unbound road sub-base. Construction and Building Materials. 20: 578-585.

Rao, A., Jha, K.N. \& Misra, S. 2007. Use of aggregates from recycled construction and demolition waste in concrete. Resources, Conservation and Recycling. 50: 71-81.

O’Mahony, M.M. \& Milligan, G.W.E. 1991. Use of recycled materials in subbase layers. Transp Res Rec. 1310:73-80.

Shah, S.A.R., Mahmood, Z., Nisar, A., Aamir, M., Farid, A. \& Waseem, M. 2020. Compaction performance analysis of alum sludge waste modified soil. Construction and Building Materials. 230: 116953.

Sivakumar, V., McKinley, J.D. \& Ferguson, D. 2004. Reuse of construction waste: performance under repeated loading. Proc Inst Civ Eng Geotech Eng. 157 (2): 91-96.

Vieira, C.S. \& Pereira, P.M. 2015. Use of recycled construction and demolition materials in geotechnical applications: A review. Resources, Conservation and Recycling. 103: 192-204.

Yadav, J.S., Hussain, S., Tiwari, S.K. \& Garg, A. 2019. Assessment of the load-deformation behaviour of rubber fibre-reinforced cemented clayey soil. Transportation Infrastructure Geotechnology. 6-2: 105-136. 